\title{
Study on Air Pollution Control in China from the Perspective of Public Health
}

\author{
Long Yin \\ School of economics, Harbin University of Commerce, Harbin 150028, China
}

Keywords: Public Health, Air Pollution, Regulation

\begin{abstract}
Since the reform and opening up, China's economic development has made remarkable achievements, but environmental pollution problems have become increasingly serious, which are caused by the extensive economic development. At present, China's regulatory strength is weak, the market mechanism is not perfect, and how to control air pollution is a critical issue for us. Based on the analysis of the plight of China's environmental governance, this paper puts forward the effective way to realize the air pollution control in china.
\end{abstract}

\section{Introduction}

Since the reform and opening up, the reform and innovation of the system have created a huge economic dividend for China, achieved the rapid economic development, attracting worldwide attention as "China miracle". But "high input, high energy consumption, high pollution," the "black" extensive development model to the environment has brought a huge impact, frequent environmental pollution incidents. At present, China's economy has entered a new stage, facing the dual challenges of economic downturn and increasingly serious ecological and environmental problems, "China miracle" can continue to become the focus of social concern. As the world's largest carbon emitter, China will face greater pressure on carbon emissions, in the process of industrialization, urbanization ,and strive to achieve peak carbon emissions by 2030, and achieve the goal of carbon emission reduction. The fog in China is becoming more and more serious, the pollution is getting deeper and deeper, and the coverage is more and more widespread. Seven of the world's most polluted 10 cities in China. Air pollution not only affects people's production and life, but also has a negative impact on the economy.

At the same time, air pollution seriously endanger public health, a large number of medical literature research found that air pollution particles will directly enter and adhesion in the human respiratory tract and lungs, will hinder the normal circulation of blood, causing respiratory, cardiovascular and cerebrovascular diseases. China's growing air pollution has seriously threatened public health, increased people's medical burden, resulting in a huge loss of social welfare. The incidence of respiratory system diseases, lung cancer and cardiovascular and cerebrovascular diseases, which is closely related to air pollution, is increasing year by year, and lung cancer is the leading cause of cancer death in china. In 2015, "air pollution prevention law" the third amendment, put forward to control air pollution to improve the atmospheric environmental quality as the goal, to reduce air pollution emissions to air quality requirements to meet the public health importance, especially the protection of public health.

With the air pollution caused a series of public health problems, people on the "beautiful scenery" increasingly strong voice. The implementation of green development to the atmospheric environment governance, it is necessary to form a government, enterprises, the public three common governance environment governance system. The government should adopt a more stringent and effective environmental policy, the new reform policy not only to continue to create economic dividends, but also to create environmental dividends, improve public health. Enterprises should comply with national policies, change the mode of production, the reality of green innovation. At the same time, the public should play a good supervisory role in the issue of air pollution control. 


\section{The Dilemma of China 's Air Pollution Control}

The environmental policy of the country is related to the coordination and balance between economic growth and environmental protection and public health. China's dual economic characteristics determine that any policy can not be used in a one-size-fits-all manner, because the differences in factor endowments between different regions, different industries, and different firms determine that emissions rights differ significantly in the income of different economies. Take the theory of emissions trading mechanism can improve the efficiency of resource allocation, promote energy saving and emission reduction effect, which can improve public health, but also can promote the economic growth of the goal of governance, is the best choice to solve the problem of air pollution. However, in the process of concrete practice, there are two difficulties.

Imperfect market mechanism. In China, carbon emissions trading pilot policy has little effect, more like a forgotten general environmental policy, the effect of administrative orders is relatively obvious. The practice of regulation in developed countries has proved that the mature market mechanism can continue to produce efficient economic benefits, because excessive administrative intervention hinders the formation of effective mechanisms to some extent. China's emissions trading pilot policy is difficult to implement, the pilot has not been fully implemented for many years, has never been effectively functioning, it is simply inefficient trading market. At the same time, there are many shortcomings in its mechanism design, mainly in: the distribution system of emission rights is imperfect, the rules of the transaction are inefficient, the monitoring ability and the system are missing, the transaction cost is too high and the transaction process is complicated.

Weak environmental regulation. Strong environmental regulation can guarantee environmental protection policy to play an effective environmental improvement effect, weak environmental regulation is not. At present, the intensity of environmental regulation in China is very weak. Even if the market operates effectively and the optimal allocation of resources is achieved, the emission trading mechanism can not achieve good results. According to the reports released by YCELP and CIESIN, China's overall environmental regulation intensity index is -0.58, ranking 115th in 146 countries and regions, far behind the average level of developed countries. China's environmental regulation is generally weak, specifically in: environmental regulations are not sound, policy implementation is poor, the implementation of regulatory policies are often obstructed by local governments, environmental governance is often caught in the rules, rules do not follow the situation. During the long period of reform and opening up, the local governments have been caught in the dilemma of "pollution first" and "post governance" in the pursuit of "economic development as the primary goal" and "the development is the absolute principle".

\section{Effective way to achieve air pollution control in China}

Gradually improve the market means. The market is still in the stage of construction in China, at this stage, carbon emissions trading policy as the representative of the market means in the short term is difficult to replace the command - control mechanism, practice also confirmed that the former policy effect in the short term is also difficult to go beyond the latter. At present, the organic combination of the two types of environmental policies is more effective in achieving the goal of air pollution regulation. Therefore, the combination of the two major environmental policies is more effective. With the deepening of the degree of market construction, environmental policy should be gradually tilted to the market means to form a market-oriented means of regulation and control policy system to play its theoretical realization of economic and environmental win-win system advantage. At the same time, we also found that the strict collection of sewage charges of the region have achieved certain results, but because of the narrow coverage, low defect collection standards, only the embryonic form of the environmental tax, and gradually form a more reasonable and perfect the environmental tax system will become inevitable. The market approach of combining emission 
trading mechanism with environmental tax will become an effective way for air pollution regulation in the future.

Raise the intensity of environmental regulation. The imperfect market mechanism and weak environmental regulation intensity lead to the lack of internal and external power of technological innovation, which is the main reason for the failure of China's environmental governance market instruments to achieve theoretical results. Assuming the effective operation of the market, the existing level of environmental regulation to a certain extent, can improve the efficiency of emission rights allocation, improve environmental problems. However, at present, China's weak environmental regulation intensity still restricts the trading mechanism of emission rights, making it difficult to achieve the economic and environmental win-win regulatory objectives. In fact, the intensity of weak environmental regulation is also an important reason for the inefficiency of the market operation. It can not provide effective external environment thrust and inherent demand for market mechanism construction. On the one hand, the level of environmental regulation is weak is unable to form the effective emissions trading scale, many enterprises do not have the power to participate in market transactions, can not form a good market. On the other hand, the lack of reasonable and effective means to promote the construction of market mechanism, the market mechanism is hard to improve. At the same time, weaker environmental regulation intensity also led to command-control policy is difficult to effect, therefore, to crack the challenges of internal and external reality, focusing on improving the intensity of environmental regulation.

\section{The implementation of tripartite covenant.}

China's political structure model determines the policy in the formulation and implementation process to follow the "top-down" model, easy to form a "government initiative, business passive, the public does not move" pattern. It is difficult to achieve the economic and environmental win-win regulatory goals, and can not significantly improve the public health level. It is difficult to achieve the goal of environmental protection and environmental protection. According to the developed country and China years of practical experience, the innovation of environmental management system, the three party to form a "top-down and bottom-up" government, enterprises and the public "common governance, mutual supervision" system of governance, is expected to become the effective way to carry out environmental regulation in China. From the three party co-governance, strengthening environmental regulation requires both the government departments to introduce environmental policies and environmental legislation, and the public's active participation in environmental protection and media coverage of related pollution incidents. Among them, the environmental legislation is the key to the implementation of environmental policies, strengthen law enforcement can bring considerable reductions, and effective supervision of the public is to increase the intensity of environmental regulation and promote environmental policy and perfect power. Public participation in the successful cases in developed countries in environmental governance, but also makes for the public participation has become the new developing power to solve environmental regulation, weak in dealing with environmental problems, especially in air pollution control, encourage public participation will contribute to the improvement of environmental quality.

\section{Acknowledgment}

This work is supported by National Social Science Fund Project 16BJY125, and Hei Longjiang Province Philosophy Social Science Project 16EDB05.

\section{References}

[1] Qun Bao, Min Shao, Dali Yang. Environmental Regulation, Provincial Legislation and Pollution Emission in China. Economic Research Journal. Vol.48 (2013) p.42-54.

[2] Shuo Chen, Ting Chen. Air Pollution and Public Health:Evidence from Sulfur Dioxide Emission of Coal-fired Power Stations in China. Economic Research Journal. Vol.49 (2014) p.158-169. 
[3] Zhengge Tu, Renjun Kan. Industrialization's, Urbanization's Dynamic Marginal Carbon Emissions The Analytical Framework Based on LMDI "Two-Level Perfect Decomposition" Method. China Industrial Economics. Vol.30 (2013) p.31-43.

[4] Tu Zhengge, Kan Renjun. Can Emissions Trading Scheme Achieve the Porter Effect in China?. Economic Research Journal. Vol.50 (2015) p.160-173.

[5] Jianxiang Wan, Guoping Mei. Can Social Capital Drive Economic Growth and Environmental Protection?. The Journal of Quantitative \& Technical Economics. Vol.29 (2012) p.61-75. 